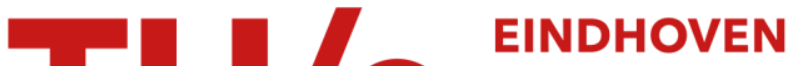 \\ UNIVERSITY OF \\ TECHNOLOGY
}

\section{Wireless Optical PPM Telemetry and the Influence of Lighting Flicker}

\section{Citation for published version (APA):}

Otte, R., Jong, de, L. P., \& Roermund, van, A. H. M. (1998). Wireless Optical PPM Telemetry and the Influence of Lighting Flicker. IEEE Transactions on Instrumentation and Measurement, 47(1), 51-55.

https://doi.org/10.1109/19.728788

DOI:

10.1109/19.728788

Document status and date:

Published: 01/01/1998

\section{Document Version:}

Publisher's PDF, also known as Version of Record (includes final page, issue and volume numbers)

\section{Please check the document version of this publication:}

- A submitted manuscript is the version of the article upon submission and before peer-review. There can be important differences between the submitted version and the official published version of record. People interested in the research are advised to contact the author for the final version of the publication, or visit the $\mathrm{DOI}$ to the publisher's website.

- The final author version and the galley proof are versions of the publication after peer review.

- The final published version features the final layout of the paper including the volume, issue and page numbers.

Link to publication

\section{General rights}

Copyright and moral rights for the publications made accessible in the public portal are retained by the authors and/or other copyright owners and it is a condition of accessing publications that users recognise and abide by the legal requirements associated with these rights.

- Users may download and print one copy of any publication from the public portal for the purpose of private study or research.

- You may not further distribute the material or use it for any profit-making activity or commercial gain

- You may freely distribute the URL identifying the publication in the public portal.

If the publication is distributed under the terms of Article 25fa of the Dutch Copyright Act, indicated by the "Taverne" license above, please follow below link for the End User Agreement:

www.tue.nl/taverne

Take down policy

If you believe that this document breaches copyright please contact us at:

openaccess@tue.nl

providing details and we will investigate your claim. 


\title{
Wireless Optical PPM Telemetry and the Influence of Lighting Flicker
}

\author{
Rob Otte, Leo P. de Jong, and Arthur H. M. van Roermund, Senior Member, IEEE
}

\begin{abstract}
Digital pulse-position modulation (PPM) is attractive to apply in wireless optical-telemetry systems because of its power efficiency. Usually, the bit-error rate is assumed to depend solely on the noise level. The detrimental influence of optical interference is overlooked. In this paper, interference measurements are reported, models that describe interference are presented, and it is shown that the influence of interference can be significant. Further, new rules for system design in the presence of interference are reported. It appears that, compared with the influence of noise, the flicker of incandescent lamps is usually negligible, but the flicker of fluorescent lamps is not negligible.
\end{abstract}

Index Terms - Intensity modulation, interference, optical communication, optical modulation/demodulation, optical receivers, optical signal detection, pulse position modulation, telemetry.

\section{INTRODUCTION}

$\mathbf{I}$ N MANY situations, telemetry which uses radio systems is undesirable because of problems with respect to electromagnetic compatibility (EMC), governmental regulations on frequency allocation, or information safety. For indoor applications, wireless optical infrared telemetry can be an attractive alternative, since optical radiation is confined to the user's premises, so that the above-mentioned problems hardly occur. Therefore, infrared transmission became popular as soon as the appropriate components, such as infrared LED's and Si detectors, became available in the late 1970's [1].

In mobile telemetry systems, a limited transmitter complexity and a small power consumption are of utmost importance. In such cases, digital pulse position modulation (PPM), based on intensity modulation and direct detection, is a very suitable modulation scheme, because it combines the advantages of digital transmission (easy multiplexing of sensor signals, the possibility for data compression and error correction) and small duty-cycle pulse transmission (low-power transmitter) [2]-[4].

First, the PPM scheme and the receiver are described in Section II. The system design is based on the fact that the main source of noise is the detector shot noise caused by ambient radiation.

Second, the detrimental influence of interference caused by ambient radiation is investigated in Section III, so that the limitations of the white noise approach can be taken into

Manuscript received May 1, 1997; revised June 1, 1998.

The authors are with the Faculty of Information Technology and Systems, Department of Electrical Engineering, Delft University of Technology, 2628 CD Delft, The Netherlands (e-mail: r.otte@et.tudelft.nl).

Publisher Item Identifier S 0018-9456(98)05480-1.

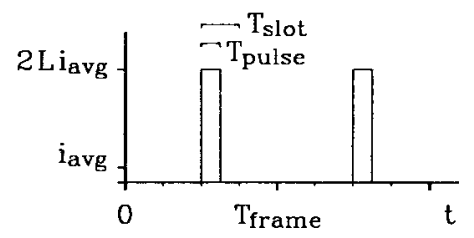

Fig. 1. The PPM modulation scheme.

account, and new design rules to overcome the influence of interference are derived.

Finally, Section IV summarizes the conclusions.

\section{Modulation, Synchronization, AND Demodulation}

In a PPM modulator, an input word consisting of several bits is converted into the position of a pulse within a frame. This is shown in Fig. 1. The frame, with duration $T_{\text {frame}}$, is divided into $L$ slots with duration $T_{\text {slot }}$ and only one of these slots contains an optical pulse. Since $L$ possible pulse positions are used to code $\log _{2} L$ bits of information, the bit rate follows as $R_{b}=\log _{2} L / T_{\text {frame. Initially, we assume the }}$ pulses to be rectangular. The height of the pulses is normalized such that the average current through the receiver photodiode is $i_{\text {avg. }}$. It is an important quantity, since it depends on the transmitted optical power. Therefore, it indirectly determines the average power consumption of the transmitter and thus the battery lifetime. Because the information is represented by the position of the pulses, the receiver has to operate synchronously, i.e., it requires a slot and frame synchronization system. To facilitate slot synchronization by means of a phaselocked loop (PLL), the pulse duration is chosen to be equal to half the slot duration [3], [5]. Therefore, the scheme is also called "half-pulse PPM." This indicates the contrast with "full-pulse PPM," in which the pulse duration equals the slot duration. Apart from the slot timing, the frame timing has also to be known before demodulation is possible. By utilizing the knowledge that every PPM frame contains exactly one pulse, frame synchronization can be achieved [4].

When comparing PPM to other transmission schemes such as on-off keying, the BER and the minimally required transmission bandwidth $B$ have to be calculated.

The demodulator is assumed to be a maximum likelihood integrate-and-dump (I\&D) demodulator, i.e., a demodulator that assumes the PPM pulse to originate from the pulse interval in which most optical energy was found [6]. For adequately designed receivers, the main source of noise is the photodetector shot-noise current caused by ambient radiation. 


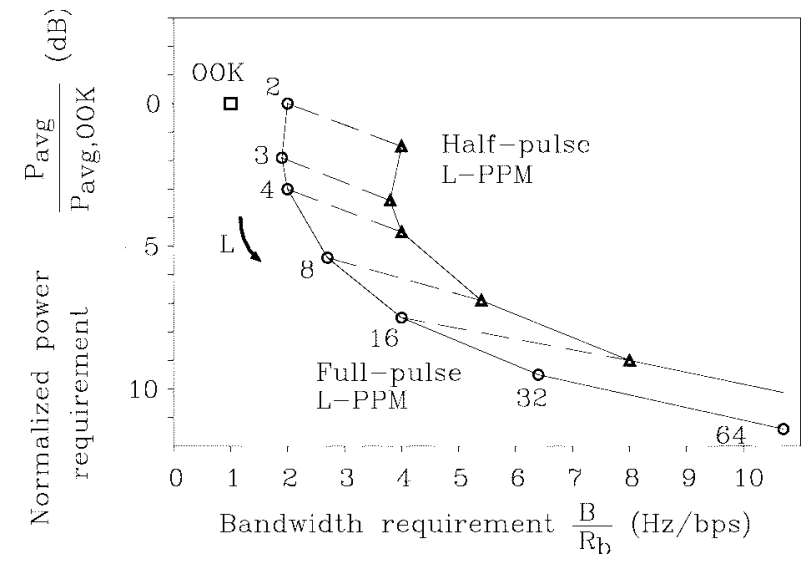

Fig. 2. Comparison of required transmitter power and required transmission bandwidth.

This white-noise process is described by its double-sided spectral density $N_{0}=q I_{\mathrm{amb}} \mathrm{A}^{2} / \mathrm{Hz}$, where $q$ is the electron charge and $I_{\mathrm{amb}}$ is the photodiode quiescent current due to ambient radiation. For Gaussian noise, the bit error rate (BER) of our demodulator can be calculated as [2], [3]

$$
\begin{aligned}
\mathrm{BER} & =\frac{L}{2} Q\left(\sqrt{L \log _{2} L} \frac{i_{\mathrm{avg}}}{\sqrt{N_{0} R_{b}}}\right) \\
& \approx Q\left(\sqrt{L \log _{2} L} \frac{i_{\mathrm{avg}}}{\sqrt{N_{0} R_{b}}}\right)
\end{aligned}
$$

in which $Q(k)=(1 / \sqrt{2 \pi}) \int_{k}^{\infty} \exp \left(-(1 / 2) \lambda^{2}\right) d \lambda$ is the noise distribution function and $i_{\text {avg }}$ is the average PPM photocurrent. In power budget calculations, the applied approximation is usually allowed, since $Q(k)$ is a rather steep function.

Subsequently, the required transmission bandwidth has to be calculated. Since the transmitter spectrum extends to infinity, an estimation has to be made. In [3], it was shown that for our demodulator $B=1 / T_{\text {pulse }}$ is a reasonable estimate.

In Fig. 2, the required transmitter power $P_{\mathrm{avg}}$, which corresponds to a detector current of $i_{\mathrm{avg}}$, and the required transmission bandwidth $B$ of full-pulse PPM and half-pulse PPM are compared in relation to on-off keying. The figure illustrates that for low-power telemetry PPM is much more suitable than on-off keying, especially when the bit rate is low compared to the available channel bandwidth. Further, it appears that transmitter power can be saved at the expense of additional transmission bandwidth by increasing the number of slots per frame $L$, thereby allowing a compromise between power consumption and transmission bandwidth.

A prototype half-pulse PPM system, with $L=4$, was realized with discrete components to verify the theory. The BER was measured at a bit rate of $5 \mathrm{kbps}$. The results are shown in Fig. 3 as a function of $k$, i.e., as a function of the argument of the function $Q(\cdot)$. The deterioration in sensitivity compared with (1) is about $0.4 \mathrm{~dB}$ (optical power level), mainly due to slot clock jitter. The maximum bit rate follows from the channel bandwidth. In our indoor telemetry application, this bandwidth is in the order of $10 \mathrm{MHz}$ due to multipath dispersion. This allows maximum data rates of about 2.5 Mbps.

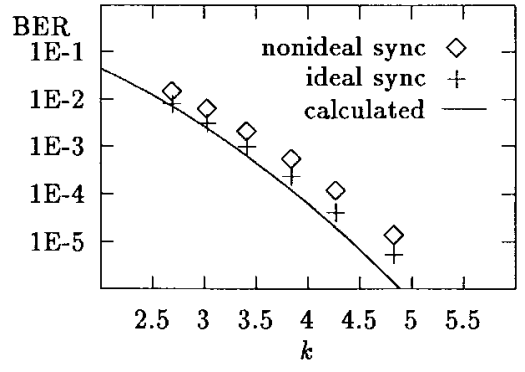

Fig. 3. Measured and calculated values of the BER versus $k$.

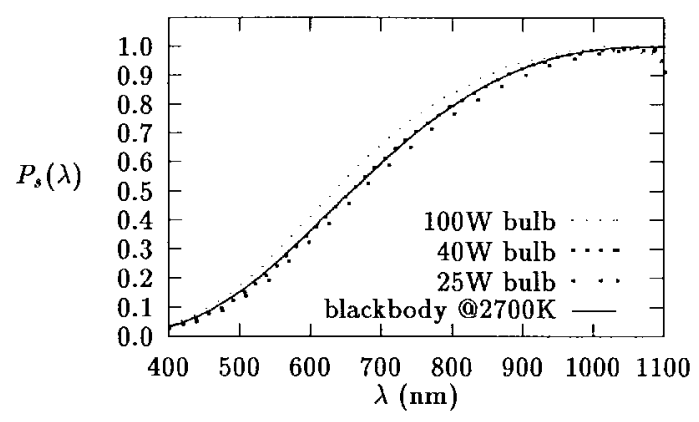

Fig. 4. Relative spectra of standard bulbs. For comparison, the spectrum of a blackbody at $2700 \mathrm{~K}$ is also shown.

\section{INTERFERENCE DUE TO AMBIENT RADIATION}

In the previous section, it was assumed that the bit error rate is determined by the detector shot noise, caused by ambient radiation. However, lighting does not only cause noise, but it might also interfere with the PPM signal because of lamp flicker. In particular, systems that have been optimized with regard to noise, by choosing a large photodetector area, are sensitive to this optical interference. Therefore, the influence of interference is investigated separately in this section. First, the amount of infrared radiation in the range $800 \mathrm{~nm}<\lambda$ $<1000 \mathrm{~nm}$ is determined for sunlight, incandescent light, and fluorescent light. Then, the modulation properties of the sources are investigated.

\section{A. The Sun}

For sunlight, the amount of infrared radiation is known [7]: the maximum solar spectral irradiance is in the range $0.25 \mathrm{~W} / \mathrm{m}^{2} \mathrm{~nm}<E_{e, \lambda}<1.0 \mathrm{~W} / \mathrm{m}^{2} \mathrm{~nm}$, so that noise levels can readily be calculated if the area, the responsivity, and the optical bandwidth of the detector are known. Modulation effects are hardly of importance.

\section{B. Incandescent Lighting}

For incandescent light, the situation is more complicated since incandescent lamps suffer from flicker due to the mains frequency. The amount of infrared radiation of several standard $230 \mathrm{~V}$ incandescent lamps was measured by means of a double monochromator. The spectra are shown in Fig. 4. Within the wavelength range considered, the lamps behave like blackbodies at a temperature of $2700 \mathrm{~K}$. For design purposes, the amount of infrared radiation relative to the 


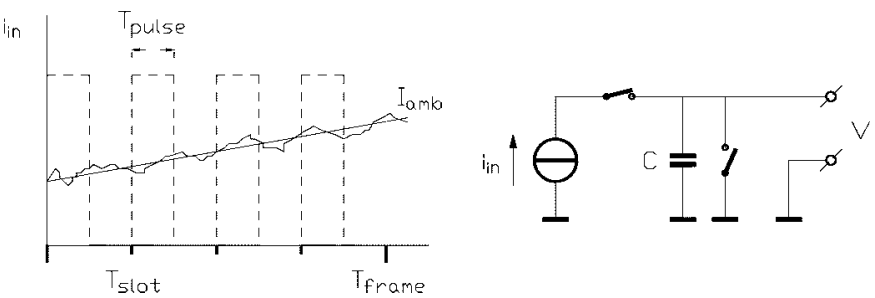

Fig. 5. Signals at the receiver input and the schematic of the I\&D demodulator filter. The input signal $i_{\text {in }}$ consists of three components: the PPM signal current, a parasitic current due to ambient radiation $I_{\mathrm{amb}}$, and the shot noise component of this latter current. The switches in the I\&D filter are controlled such that the filter is integrating during the dashed intervals.

amount of visible light is a suitable measure. Therefore, the optical spectrum was normalized to $1 \mathrm{~lm}$. The result is called the "infrared-to-visible ratio," or IRTV. For blackbodies at a temperature of $2700 \mathrm{~K}$, the IRTV is in the range $41 \mu \mathrm{W} / \mathrm{lm} \cdot \mathrm{nm}$ $<$ IRTV $<50 \mu \mathrm{W} / \mathrm{lm} \cdot \mathrm{nm}$, depending on the wavelength. The detector current due to ambient light follows from

$$
I_{\mathrm{amb}}=\int_{0}^{\infty} R(\lambda) F(\lambda) \operatorname{IRTV} d \lambda \cdot \Phi_{v} .
$$

In this expression, $R$ is the detector responsivity, $\Phi_{v}$ is the luminous flux incident on it, and $F$ is the filter transmission. The lamp flicker was measured at a mains frequency of $50 \mathrm{~Hz}$, in the wavelength span $850 \mathrm{~nm}<\lambda<1050 \mathrm{~nm}$. Due to filament lag, the ripple on the intensity is almost sine shaped, with a frequency of $f_{i}=100 \mathrm{~Hz}$ and an amplitude that approximately equals $10 \%$ of the average intensity [8]. Thus, the modulation index of the lamp is said to equal $m_{i}=10 \%$.

The influence of flicker and other intensity variations can be modeled after considering Fig. 5. In the model, we assume that the level of ambient radiation varies only slowly, compared with the PPM signal, so that its first-order derivative is satisfactory in describing its variations. Further, it is assumed that $I_{\mathrm{amb}}$ is modulated only weakly, so that the level of shot noise is approximately constant. For incandescent lamps, these approximations are valid in almost all practical situations. The maximum slope of $I_{\mathrm{amb}}$ follows from the interfering frequency and the modulation index of the lamp as

$$
\left.\frac{\mathrm{d} I_{\mathrm{amb}}}{\mathrm{d} t}\right|_{\max }=2 \pi m_{i} f_{i} I_{\mathrm{amb}} .
$$

Lamp flicker is negligible provided that the difference between the last and the first integration result, $\Delta_{i}(V)$, is smaller than the rms variations of the integration results due to noise, $\sigma_{n}(V)$. The transfer of the I\&D filter, from the input current to the output voltage at the end of an integration interval, is defined by the impulse response and its Fourier transform, respectively, as

$$
\begin{aligned}
h(t) & = \begin{cases}\frac{1}{C}, & \text { if } 0 \leq t \leq T_{\text {pulse }} \\
0, & \text { elsewhere }\end{cases} \\
H(f) & =\frac{V(f)}{i_{\text {in }}(f)} \\
& =\frac{T_{\text {pulse }}}{C} \operatorname{sinc}\left(\pi f T_{\text {pulse }}\right) \exp \left(-j \pi f T_{\text {pulse }}\right)
\end{aligned}
$$

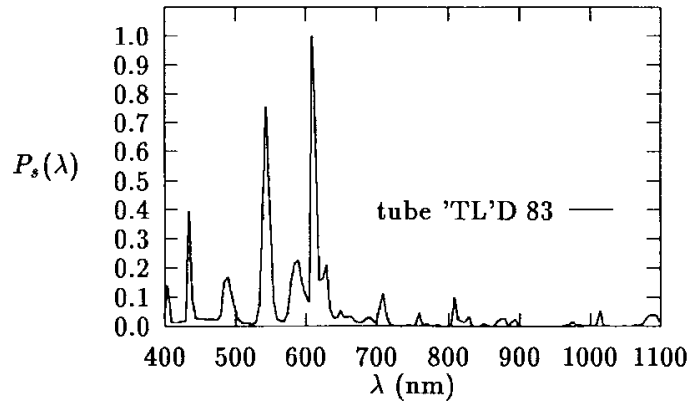

Fig. 6. Relative spectrum of fluorescent tube "TL"D 83.

with $\operatorname{sinc}(x)=(\sin (x) / x)$. From the filter response, $\Delta_{i}(V)$ and $\sigma_{n}(V)$, respectively, follow as

$$
\begin{aligned}
& \Delta_{i}(V)=\left.\frac{(L-1) T_{\text {frame }}}{L} \frac{T_{\text {pulse }}}{C} \frac{\mathrm{d} I_{\text {amb }}}{\mathrm{d} t}\right|_{\max }(V) \\
& \sigma_{n}(V)=\frac{1}{C} \sqrt{N_{0} T_{\text {pulse }}}(V) .
\end{aligned}
$$

In these expressions $C$ is the value of the capacitor in the I\&D filter. In practice, $(L-1) / L \approx 1$, since only $L \geq 4$ allows for low-power transmission, and $T_{\text {pulse }}=\left(T_{\text {frame }} / 2 L\right)$. Now $\Delta_{i}(V)<\sigma_{n}(V)$ holds provided that

$$
I_{\mathrm{amb}}<\frac{q L}{2 \pi^{2} m_{i}^{2} f_{i}^{2} T_{\text {frame }}^{3}} .
$$

This means that, in particular, systems that are optimized with regard to noise by means of a large detector area, or a large number of slots per frame, might suffer from lamp flicker. It also means that low-speed systems are more sensitive to lamp flicker than high-speed systems. In practice, (8) is only violated very close to the lamp, indicating that special measures, such as hum filtering, are not required, and that (1) remains valid.

\section{Fluorescent Lighting}

Like incandescent lamps, fluorescent lamps also suffer from flicker. In lighting systems that employ a traditional inductive ballast circuit, the flicker frequency equals twice the mains frequency. Today, high-frequency ballast circuits are often used to obtain better lamp performance. In those cases, the flicker frequency is usually in the range of $40 \mathrm{kHz}$ to $100 \mathrm{kHz}$. At the same time, the modulation index is large, i.e., in the range $50 \%$ to $100 \%$, depending on the supply frequency [8].

To investigate when lamp flicker is detrimental, the amount of infrared radiation was measured for several lamps. Since the results are approximately the same, only one of the spectra, obtained from the commonly used Philips $36 \mathrm{~W}$ tube "TL"D 83 , is given as a plot in Fig. 6. The spectral lines are partly caused by the emission lines of mercury, and partly by the emission lines of the phosphors inside the tube [9]. It appears that, at the same illuminance, fluorescent lamps produce much less infrared radiation than incandescent lamps. To investigate the amount of infrared radiation more accurately, the spectrum was normalized to $1 \mathrm{~lm}$, resulting in the IRTV plot shown in Fig. 7. This figure is used to determine the detector current from (2). 


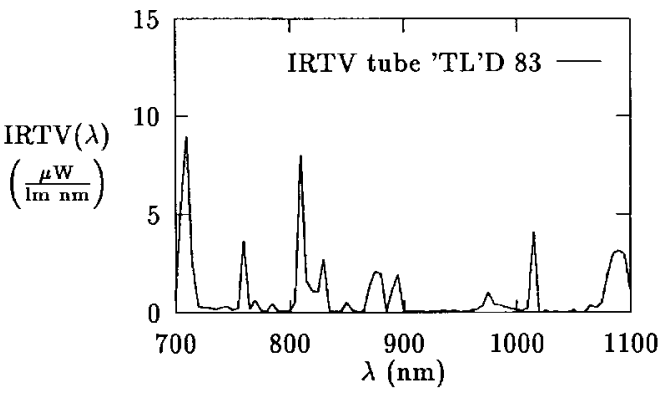

Fig. 7. IRTV of fluorescent tube "TL”D 83 (wavelength resolution $5 \mathrm{~nm}$ ).

When operated at the mains frequency, lamp flicker can be modeled as before. When operated at a high-frequency ballast circuit this is not possible, since the interfering frequency is in the order of the frame rate, or even faster. In such cases, the influence of flicker should be investigated per slot. Again, the interfering signal can be approximated as a sine wave. The rms variations of the integration results due to flicker equal

$$
\sigma_{i}(V)=\left|H\left(f_{i}\right)\right| i_{i}(V) .
$$

In this expression $i_{i}=(1 / 2) \sqrt{2} m_{i} I_{\mathrm{amb}}$ is the rms value of the interfering current and $f_{i}$ is its frequency. Lamp flicker is negligible compared to noise provided that $\sigma_{i}(V)<\sigma_{n}(V)$. This requirement holds provided that

$$
I_{\text {amb }}<\frac{2 q}{T_{\text {pulse }} m_{i}^{2} \operatorname{sinc}^{2}\left(\pi f_{i} T_{\text {pulse }}\right)} .
$$

\section{Design Example}

In this example, we investigate the influence of fluorescent lamp flicker on the link quality of a $100 \mathrm{kbps}$ half-pulse 4-PPM system. The flicker frequency of the lamp is $f_{i}=100 \mathrm{kHz}$. Its modulation index is $50 \%$. Since the bit rate is $100 \mathrm{kbps}$, the system has $T_{\text {frame }}=20 \mu \mathrm{s}$ and $T_{\text {pulse }}=2.5 \mu \mathrm{s}$. The detector has an area of $A_{\text {det }}=200 \mathrm{~mm}^{2}$, a responsivity of $R=0.6$ $\mathrm{A} / \mathrm{W}$, and an optical bandwidth of $B_{\mathrm{opt}}=100 \mathrm{~nm}$ centered at $900 \mathrm{~nm}$. The detector is illuminated at a level of $E_{v}=500$ $\mathrm{lm} / \mathrm{m}^{2}$. This illumination is typical of desktops in offices.

The detector current follows from (2) as $I_{\mathrm{amb}}=$ $R \int_{850 \mathrm{~mm}}^{950 \mathrm{~nm}} \operatorname{IRTV} \mathrm{d} \lambda \Phi_{v}=2.9 \mu \mathrm{A}$, and we find

$$
\sigma_{i}(V)=\frac{2.32 \cdot 10^{-12}}{C}>\sigma_{n}(V)=\frac{1.08 \cdot 10^{-15}}{C}(V) .
$$

Clearly, the effect of lamp flicker exceeds the effect of noise by far, even when the receiver is not very close to the lamp. The reason is that, on the one hand, the noise level is low, since the level of infrared radiation is low, while, on the other hand, the effect of flicker is large, since the modulation index is large and the flicker frequency is close to the slot rate. Even when the lamp is operated at the mains frequency, lamp flicker is usually more detrimental than noise. Thus, (1) is not a suitable design rule. Instead, one has to be ensured that the integration result caused by the PPM pulse, which has a value of $\left(T_{\text {frame }} / C\right) i_{\mathrm{avg}}$, exceeds the variation of the integration results due to lamp flicker as given by (6) or (9).

\section{CONCLUSIONS}

In this paper, measurements of the influence of optical interference on the link quality have been described and modeled. Design rules to overcome the effect of interference were derived. It appears that the flicker of incandescent lamps is often negligible when compared with the detrimental effect of shot noise. Flicker of fluorescent lamps cannot be neglected, particularly when the lamps are driven from high-frequency ballast circuits.

\section{ACKNOWLEDGMENT}

The authors would like to thank Dr. C. A. Schrama and Mr. H. W. Reyn at the Nederlands Meetinstituut (NMi), for their contributions to the spectral calibration of the monochromator and the measurements of the optical spectra.

\section{REFERENCES}

[1] F. R. Gfeller and U. Babst, "Wireless in-house data communication via diffuse infrared radiation," Proc. IEEE, vol. 67, Nov. 1979

[2] J. R. Barry, Wireless Infrared Communications. Boston, MA: Kluwer, 1994.

[3] R. Otte, "Low-power wireless optical transmission," Ph.D. thesis, Delft Univ. Technology, Delft, The Netherlands, 1998.

[4] R. Otte, L. P. de Jong, and A. H. M. van Roermund, "Synchronization in wireless optical PPM transmission systems," in Proc. PRORISC/IEEE Workshop Circuits, Systems, Signal Processing, Mierlo, The Netherlands, Nov. 1996, pp. 249-254.

[5] V. A. Vilnrotter and E. R. Rodemich, "A synchronization technique for optical PPM signals," in Proc. IEEE Military Com. Conf. (MILCOM'86), Monterey, CA, Oct. 1986, vol. 3, pp. 45.2.1-45.2.6.

[6] R. Otte, L. P. de Jong, and A. H. M. van Roermund, "A novel PPM demodulator for wireless optical transmission systems," in Proc. Electronics'96, Sozopol, Bulgaria, Sept. 1996.

[7] R. Hulstrom, R. Bird, and C. Riordan, "Spectral solar irradiance data sets for selected terrestrial conditions," Solar Cells, vol. 15, Dec. 1985

[8] R. Otte, "The influence of ambient light on wireless infrared transmission systems: Noise and interference," Internal Rep., Delft Univ. Technology, Delft, The Netherlands, Jan. 1997.

[9] J. R. Coaton and A. M. Marsden, Eds., Lamps and Lighting. London, U.K.: Arnold, Hodder, 1997.

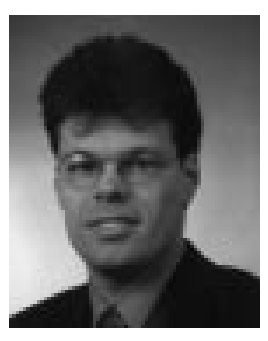

Rob Otte was born in Rotterdam, The Netherlands, in 1970. He received the M.Sc. degree in electrical engineering from the Delft University of Technology, Delft, The Netherlands, in 1992, where he is currently pursuing the Ph.D. degree.

He is now with Philips Research Laboratories, Eindhoven, The Netherlands, where he is involved in signal processing and electronics for optical disc systems. His research interests include optical communications, modulation and synchronization, and analog circuit design.

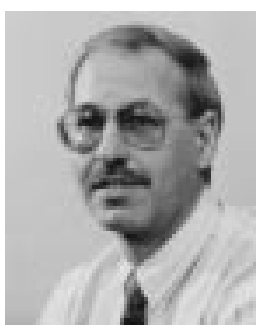

Leo P. de Jong was born in Bolsward, The Netherlands, on April 2, 1945. He received the M.Sc degree in electrical engineering from the Delft University of Technology, Delft, The Netherlands, in 1969.

Since 1971, he has been a member of the scientific staff of the Electronics Research Laboratory, Delft University of Technology, where he is presently an Associate Professor. His research interests include analog circuit design with emphasis on applications in the field of sensor interfacing, integrated radio, and fiber-optic communication systems 


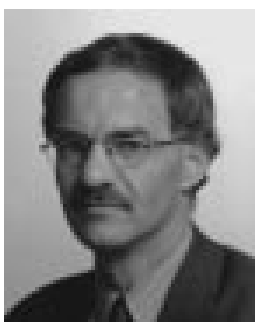

Arthur H. M. van Roermund (M'83-SM'95) was born in Delft, The Netherlands, in 1951. He received the M.Sc. degree in electrical engineering in 1975 from the Delft University of Technology and the Ph.D. degree in applied sciences from the Katholieke Universiteit Leuven, Leuven, Belgium, in 1987.

From 1975 to 1992, he was with Philips Research Laboratories, Eindhoven, The Netherlands, involved successively in analog electronics, programmable digital video signal processors, video algorithm design, architectures for video, and multiwindow television. Since 1992, he has been a Full Professor in the Electrical Engineering Department of Delft University of Technology, where he is Chairman of the Electronics Department. His group is active in low-power and low-voltage electronics, RF and optic communication electronics, sensor electronics, high-temperature electronics, video techniques, nonlinear analog signal processing, neural networks, nano-electronics, and EMC. He is participating in DIMES (the Delft Institute of Micro Electronics and Submicron technology), which activities are in the field of micro-electronic circuits and systems, technology and devices, and IC-related physics. Within DIMES, he heads the Electronics Group and coordinates the Circuits and Systems Sector. He is Chairman of a two-year postgraduate school for "chartered designer." From 1992 to 1997, he was a Consultant for Philips. He is Chairman of the Board of ProRISC, a nationwide micro-electronic platform. 